\title{
MMED PROJECT
}

\section{The Clinical Profile of Takayasu Disease at Tygerberg Academic Hospital - a retrospective study}

Amani Kaawan ${ }^{1 *}$, Mou Manie ${ }^{1}$, Adel M Aboshakwa², Razeen Davids ${ }^{3}$

${ }^{1}$ Division of Rheumatology, Tygerberg Academic Hospital, National Health Laboratory Services. Faculty of Health Sciences, Stellenbosch

University and Tygerberg Academic Hospital, Cape Town, South Africa

${ }^{2}$ Department of Medicine, Stellenbosch University and Tygerberg hospital

${ }^{3}$ Division of Nephrology, Department of Medicine, Stellenbosch University and Tygerberg Hospital

*Corresponding Author: Amani Kaawan, Division of Rheumatology, Tygerberg Academic Hospital, National Health Laboratory Services. Faculty of Health Sciences, Stellenbosch University and Tygerberg Academic Hospital, Cape Town, South Africa.

Received Date: November 02, 2020; Accepted Date: November 12, 2020; Published Date: November 19, 2020

Citation: Amani Kaawan., Mou Manie., Adel M Aboshakwa., Razeen Davids., (2020) MMED PROJECT The Clinical Profile of Takayasu Disease at Tygerberg Academic Hospital - a retrospective study. J. Clinical Cardiology and Cardiovascular Interventions, 3(11); Doi:10.31579/2641-0419/0103 Copyright: (c) 2020 Amani Kaawan, This is an open-access article distributed under the terms of the Creative Commons Attribution License, which permits unrestricted use, distribution, and reproduction in any medium, provided the original author and source are credited.

\begin{abstract}
:
Takayasu's arteritis (TA) is a disease of unknown etiology that causes chronic inflammation of the large blood vessels and usually involves the aorta and its branches. The inflammatory process initially leads to thickening of the arterial wall and may result in stenosis, occlusion, dilatation or aneurysm formation. Although TA occurs more commonly in certain regions such as Asia, it is a global disease. Currently, there is a dearth of information on this condition in African countries, including South Africa.

Results: We have identified 50 patients meeting the ACR criteria for the diagnosis of TA. Data was drawn from the records of the Division of Rheumatology as well as the angiographic records of TA. This included patient demographics, mode of presentation, classification, co-morbidities, complications, clinical and laboratory features, radiological findings, drug therapy as well as outcomes. The cohort comprised 34 of mixed race, 12 black and 4 white patients. The mean age at diagnosis was 16-56 (28.2) years. The most common presention was hypertension, followed by CVA, heart failure, and syncope. Angiography revealed Type V (most of aorta) and Type I (aortic arch branches) lesions to be the most common and that stenosis was much more common than aneurysm formation. Two patients had concomitant antiphospholipid syndrome. Another two had concomitant internal jugular vein thrombosis. Six patients had significant mediastinal lymphadenopathy, only one of whom had TB.

Corticosteroids and additional immunosuppressive therapy were used to control disease activity in most patients. Biological treatment was used in two patients. Surgical intervention consisted mainly of renal auto transplantation. Twelve percent of patients had repeated admissions, which included planned surgical intervention. We had two mortalities, both as a result of massive strokes. The mortality rate was $6 \%$. Only 3 patients had active TB.

Conclusion: The study revealed gender and age characteristics similar to previous studies, confirming that TA affects mainly young females. The mortality rate of $6 \%$ in this cohort is significantly lower than that of previous series. The unusual findings in this study were:

Significant chest lymphadenopathy in $12 \%$ of the cases,the significantly lower percentage of active TB of only $6 \%$, two cases of a rare finding of venous thrombosis as well as 2 cases of an uncommon finding in TA of antiphospholipid syndrome.
\end{abstract}

\section{Contents}

Introduction Error! Bookmark not defined.

Background. 2

Objectives . 4 
Methods ...... 4

Study design 4

Study population and sampling ... 4

Ethical and legal considerations. 4

Results .. 4

Gender distribution 4

Ethnic distribution of patients ... 4

Patient age distribution. Error! Bookmark not defined.

Presentation. 5

Pulse deficit. 5

Co-morbidity 6

Angiographic classification

Complications 7

Incidence of HIV among Takayasu patients

Incidence of Tuberculosis among Takayasu patients

Imaging

Angiographic (CTA) findings

Error! Bookmark not defined.

Medical treatment

Error! Bookmark not defined.

Surgical interventions 9

Mortality rates

Error! Bookmark not defined.

Discussion 9

Demographics 9

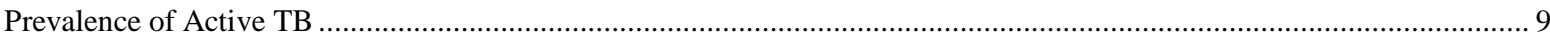

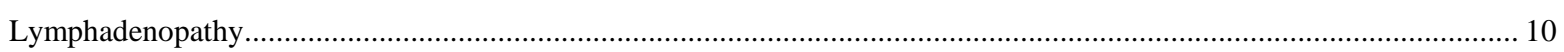

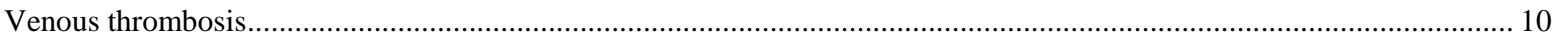

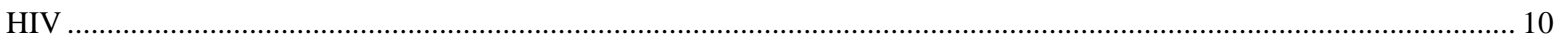

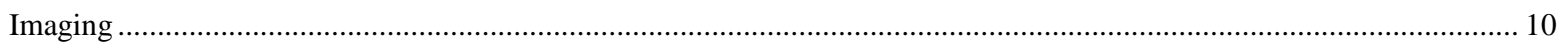

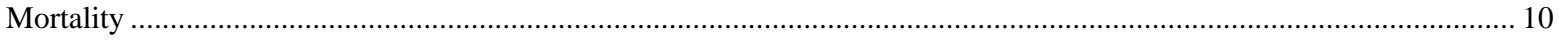

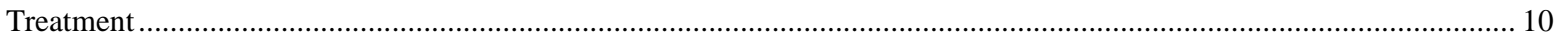

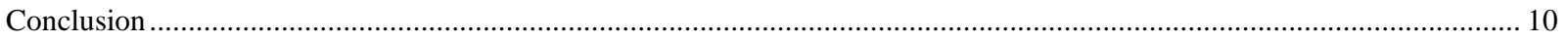

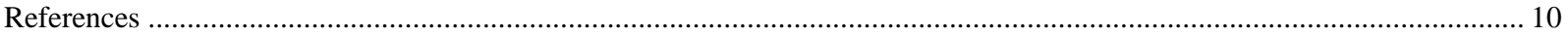

\section{Introduction}

\section{Background}

Takayasu's arteritis (TA) is a disease of unknown etiology that causes chronic inflammation of the large blood vessels and usually involves the aorta and its branches. The inflammatory process initially leads to thickening of the arterial wall and may result in stenosis, occlusion, dilatation or aneurysm formation. Although it is a rare disease, TA has worldwide distribution and is generally thought to be more common among Asian populations with an estimated incidence of 2 to 3 cases per million people annually in these regions. [1] The disease manifestations vary between populations but appear to be more common in females of child-bearing age. The majority of published studies report female to male ratios ranging between 5 and 12. [2] Another study from Korea suggested that, gender ratio rather than the ethnic differences was responsible for the differences in the distribution of the vessels affected. [3]

The diagnosis of TA may be difficult because of the non-specific nature of the illness in the early stages. Furthermore, TA exhibits different patterns of arterial involvement, disease expression and prognosis in different regions of the world. [1] The clinical presentation results from the arterial lesions and the systemic inflammatory response. At disease presentation or during relapses, TA patients may present with nonspecific complaints such as fever, malaise, anorexia, weight loss, myalgia 
or arthralgia. [2] As arterial lesions progress, more characteristic features of TA may be found such as limb claudication, decreased or absent peripheral pulses, vascular bruits, hypertension and discrepancies in blood pressure between arms due to stenotic or occlusive lesions. [1] In severe cases, this may result in serious complications such as myocardial infarction, stroke and blindness. [3]

Imaging modalities are central to establishing the diagnosis of TA, determining the distribution of lesions and monitoring disease activity. [3] Conventional radiographic angiography [digital subtraction angiography (DSA)] is considered as the gold standard for the diagnosis of TA. However, it is invasive, poses some radiation risk and currently, has largely been replaced by computerized tomography angiography (CTA). Other non-invasive imaging methods including magnetic resonance angiography (MRA), color Doppler ultrasound (CDU), PET with 18F-fluorodeoxyglucose (18F-FDG) and 18F-FDG PET/CT have recently gained ground. In a study conducted in 2004, it was shown that non-invasive imaging methods, deoxyglucose positron emission tomography (PET) and magnetic resonance imaging (MRI)) provided important additional information about disease activity and progression of vessel wall thickening when compared with $\mathrm{X}$ ray angiography. [4]A meta-analysis done to assess the diagnostic value of 18-FDG-PET in estimating disease activity in TA concluded that 18-FDG-PET had moderate diagnosis value in assessing TA activity and may add additional value to the current diagnosis methods. [5]

The goal of treatment are to stop the acute inflammatory process and prevent further damage to the vessel wall. The mainstay of therapy is glucocorticoids (usually prednisone); however, other medications include cytotoxic drugs, such as methotrexate, which are often used to help control the disease and reduce the need for prednisone. Newer agents include mycophenolate leflunomide and biologics such as TNF alpha blockers (infliximab, etanercept), tocilizumab, abatacept and rituximab are also increasingly being used for treatment of resistant cases. [3] Treatment of symptomatic fibrotic lesions (stenosis or occlusions) requires either vascular interventional or surgical therapy. This can be achieved by angioplasty with or without stenting or in severe cases, by vascular resection and surgical interventions.

\begin{tabular}{|c|c|c|c|c|c|c|}
\hline \multirow{2}{*}{ Study } & \multirow{2}{*}{$\begin{array}{l}\text { Number } \\
\text { of } \\
\text { patients }\end{array}$} & \multirow[t]{2}{*}{ Age } & \multicolumn{2}{|c|}{ Gender } & \multirow{2}{*}{$\begin{array}{c}\text { Period of } \\
\text { study }\end{array}$} & \multirow[t]{2}{*}{ Ethnicity } \\
\hline & & & Female & Male & & \\
\hline $\begin{array}{lcr}\text { South Africa } & \text { (Western } \\
\text { Cape, Groote } & \text { Schuur } \\
\text { Hospital) } & & \\
\end{array}$ & 272 & $\begin{array}{l}14-66 \\
(25.0)\end{array}$ & $75.0(n=204)$ & $25.0(\mathrm{n}=68)$ & 50 years & white \\
\hline South Africa (Gauteng) & 31 & 8.42 & $58.1 \%(18)$ & $41.9 \%(13)$ & 15 years & Black \\
\hline Tunisia & 27 & $\begin{array}{l}16-68 \\
(33.2)\end{array}$ & $88.9(n=24)$ & $11.1(n=3)$ & 20 years & Arab \\
\hline Tunisia & 11 & $\begin{array}{l}17-50 \\
(29.1)\end{array}$ & $100(n=11)$ & None & 12 years & Arab \\
\hline Morocco & 47 & $\mathrm{n} / \mathrm{a}$ & $\mathrm{n} / \mathrm{a}$ & $\mathrm{n} / \mathrm{a}$ & 11 years & Arab \\
\hline
\end{tabular}

As shown in (table 1), currently there is a paucity of data on TA from the African continent including South Africa. A literature search has revealed only 3 publications on TA from South Africa. One important study was conducted at the Groote Schuur Hospital (GSH) in Cape Town (South Africa). [21] The study reported on 272 patients over a fifty-year period (1952-2002). Patients had a mean age of twenty-five years, of which $75 \%$ were female and comprised predominantly mixed race (68\%).Some limitations of the study included a lack of information on non-vascular symptoms, the use of outdated imaging techniques, older treatment regimens as well as lack of information on co-morbidities such as HIV, diabetes and atherosclerosis. Additionally, the study reported the use of anti-TB therapy without definite confirmation of the TB diagnosis in some of the cases. Another study reporting on paediatric cases in Gauteng (South Africa) was conducted over a period of fifteen years and included thirty-one patients with a higher prevalence of TA among black patients. [3] This particular study was conducted at the Baragwanath Hospital (Johannesburg, South Africa). [3] The third study was conducted at the King Edward VIII Hospital in Durban (South Africa) and was a small series (11 patients) reporting mainly on the morphological and radiographic features of TA. [3]

A publication from Tunisia in 2010 reported on 27 patients with a mean age of diagnosis was 33 years and $88.9 \%$ were females. [3] A second Tunisian study included a limited number of 11 females and was conducted over a 12 year period, wherein the mean age at the time of diagnosis was 29.1 years. [3] Furthermore, other published studies from the African continent was from Morocco with 47 patients. [3]

Studies from other regions in the world revealed comparable data. A Turkish study included 248 patients from fifteen different rheumatology centres. Results indicated that the mean age was 40 years and the majority (228 out of 248) were females. [3] These findings are supported by a Brazilian study (Sao Paulo) wherein data was collected from three different public universities (UNIFESP, USP, UNICAMP). Seventy-three patients were recruited and showed a mean age of 27 years, with a predominantly female gender. [4]

In terms of its association with $\mathrm{TB}$, tuberculosis has remained an important differential and possible etiological factor. However, tuberculous aortitis tends to cause erosion of the vessel wall with the formation of true or false aneurysms, particularly affecting the descending thoracic and abdominal aorta. Dissection and rupture are important complications rather than the stenosis typical of Takayasu arteritis. The incidence of rupture and bleeding complications of aneurysmal Takayasu arteritis is low. previous studies reported that the association ranged from $5.0 \%$ to $48.0 \%$. However, there was also a lack of information on whether the TB was active or not and, in some cases, the diagnosis of TB appeared questionable. The question of an association of TA with HIV has also not been addressed in previous studies from this region, even 
though HIV is known to cause thrombosis of large vessels. Information and previous reports on other features of the disease also appear scarce, with special reference to the systemic features such as fever, malaise, lymphadenopathy, weight loss, skin rash, synovitis and anemia.

Studies relating to the main affected arteries of TA in this country is limited. In terms of the most common subtype of TA in South Africa, reports appear varied due to the different demographic profile and regional differences. There is also very limited information on the use of the latest imaging techniques employed for the diagnosis of TA, the treatment regimes, responses and adverse effects to treatment.

Lastly, complications such as arterial aneurysm rupture, angioplasty and surgical bypass of vascular occlusive lesions which require surgical intervention have not been reported on in any significant detail in previous studies. It should be noted that indications for surgery such as revascularization have also been changed over the last few years.

This study attempts to shed light on some of the unresolved areas referred to above.

\section{Objectives}

The aims of the study were to determine and describe:

-demographics such as age, gender and race;

-prevalence of TA in the South African region;

-the type of association with active or previous TB or HIV;

- the presenting features and the prevalence and of other co-morbidities in TA patients; -the affected arteries in TA patients;

-the imaging techniques employed for TA diagnosis;

-the treatment regimes, responses and outcomes treatment;

\section{Methods}

\section{Study design}

The current study was done at Tygerberg Academic Hospital, a tertiary referral center situated in the city of Cape Town (Western Cape Province, South Africa). Tygerberg Academic Hospital provides a tertiary service to a population of approximately 1.5 million people (the TBH drainage area). Most of the patients who visit the hospital are indigent and are of mixed-race ethnicity.

This was a retrospective observational study, conducted at the Division of Rheumatology at this hospital. Case records of patients with TA meeting the 1997 American College of Rheumatology (ACR) classification criteria were reviewed. Data collected were TA patient demographics, presentations, classification, co-morbidities, complications, clinical and laboratory features, radiological findings, drug therapy and outcomes. Data was accessed from the administrative databases of the Division of Rheumatology at Tygerberg Academic Hospital, allowing the investigator to review the in-patient and out-patient records of the TA patients.

\section{Study population and sampling}

The inclusion criteria were the positive diagnosis of TA according to ACR criteria, which requires that at least three of the six criteria are met (see Table 2 below). [2]

\begin{tabular}{|l|l|}
\hline \multicolumn{1}{|c|}{ Criterion } & \multicolumn{1}{c|}{ Definition } \\
\hline 1.Age at disease onset $<40$ years & $\begin{array}{l}\text { Development of symptoms or findings related to Takayasu's arteritis at age < } \\
\text { 40 years }\end{array}$ \\
\hline 2.Claudication of extremities & $\begin{array}{l}\text { Development and worsening of fatigue and discomfort in muscles of one or } \\
\text { more extremity while in use, especially the upper extremities }\end{array}$ \\
\hline 3.Decreased brachial artery pulse & Decreased pulsation of 1 or both brachial arteries \\
\hline 4.Blood pressure difference $>10 \mathrm{mmHg}$ & Difference of $>10 \mathrm{mmHg}$ in systolic blood pressure between arms \\
\hline 5.Bruit over subclavian arteries or aorta & $\begin{array}{l}\text { Bruit audible on auscultation over one or both subclavian arteries or abdominal } \\
\text { aorta }\end{array}$ \\
\hline 6.Arteriogram abnormality & $\begin{array}{l}\text { Arteriographic narrowing or occlusion of the entire aorta, } \\
\text { its primary branches, or large arteries in the proximal upper and lower } \\
\text { extremities, not caused by atherosclerosis, fibromuscular dysplasia, or similar } \\
\text { causes; changes usually focal or segmental }\end{array}$ \\
\hline
\end{tabular}

Table 2: American College of Rheumatology criteria for clinical diagnosis of TA

\section{Ethical and legal considerations}

The study was approved by the Ethics Committee of the Faculty of Health Sciences of the University of Stellenbosch (project number (S18/09/183) and the Research Committee of the Department of Medicine, Tygerberg Academic Hospital. The study was conducted in accordance to the Helsinki Declaration as well as MRC and ICH guidelines.

The names of the participants were not mentioned in the output of the research. Where the investigator only had access to the collected data in order to ensure the confidentiality and integrity of the data.

\section{Results}

A total of 50 patients with Takayasu arteritis (TA) were identified.

\section{Gender distribution}

Females represented the majority $(82.35 \% \mathrm{n}=42)$ of patients.

\section{Ethnic group distribution of patients}

Approximately, a third of the population were of mixed ethnicity (68\% $\mathrm{n}=34)$, almost a quarter $(24 \% \mathrm{n}=12)$

indicated were of black ethnicity and a smaller percentage of patients indicated white ethnicity. 


\begin{tabular}{|l|l|c|c|}
\hline Item & Patients' age & Frequency $(\mathbf{n = 5 1 )}$ & Percentage (\%) \\
\hline 1 & Mixed & 34 & 68 \\
\hline 2 & White & 4 & 8 \\
\hline 3 & Black & 12 & 24 \\
\hline & Total & 50 & 100 \\
\hline
\end{tabular}

Table 3: Ethnic distribution of patients

\section{Patient age distribution}

Almost half of the patients $(44 \% \mathrm{n}=22)$ were between the ages of $26-35$ years, followed by less than a third (31\% $\mathrm{n}=17)$ who were between the ages of $16-25$ years. Only seven patients $(14.0 \% \mathrm{n}=7)$ belonged to the $36-45$ years age group and four patients $(8.0 \% \mathrm{n}=4)$ were in the age group of 46 and over.

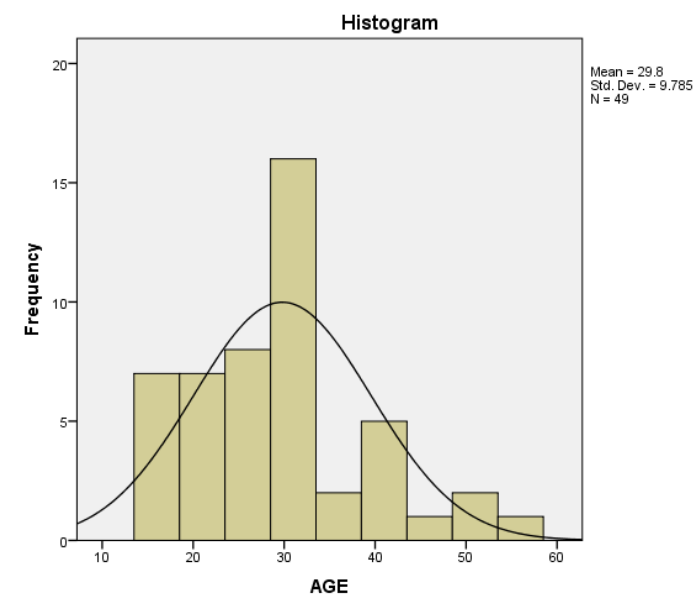

Figure 1: Age distribution of patients

\section{Presentation}

As shown in table (3), half of the patients $(50 \% \mathrm{n}=25)$ had hypertension (HPT) in their presentation, followed by eleven patients (24.0\% $\mathrm{n}=12)$ who presented with cerebrovascular accident $(C V A)$. One patient had both hypertension and CVA, and five patients $(10.0 \% \mathrm{n}=5)$ presented with heart failure (HF).

\begin{tabular}{|l|c|c|c|}
\hline Item & Presentation & Frequency & Percentage (\%) \\
\hline 1 & HPT & 25 & 50.0 \\
\hline 2 & CVA & 12 & 24.0 \\
\hline 3 & HF & 5 & 10.0 \\
\hline 4 & Syncope & 3 & 6.0 \\
\hline 5 & $\begin{array}{c}\text { Constitutional } \\
\text { symptoms }\end{array}$ & 2 & 4.0 \\
\hline 7 & Gangrene & 1 & 2.0 \\
\hline 8 & Vision loss & 1 & 2.0 \\
\hline 9 & Palpitation & 1 & 2.0 \\
\hline 10 & Missing & 2 & 4.0 \\
\hline
\end{tabular}

Table 3: distribution of presentation

The above Table refers to the main methods of presentation, some patients had more than one presenting feature which represent 5 patient $(10 \%)$ of total cohort. Of the three patients who presented with syncope, one had loss of vision; whereas one patient presented with constitutional symptoms and erythema nodosum. In the group of patients who presented with hypertension, one also had abdominal pain and BP discrepancy and another one had dry gangrene of the lower limb. Another patient also presented with lymphadenopathy. In the CVA group, one patient also had left side paresthesia and one patient also had palpitations.
Of two patients in whom we could not identify the mode of presentation, one of them was diagnosed at age of two years with no clear documentation of his presentation and the other had incomplete documentation. Significant lymphadenopathy was found in six patients $(12 \% \mathrm{n}=6)$ which refers to "pathological" lymph nodes of $2 \mathrm{~cm}$ or more, particularly in the hilar or mediastinal region. The regions in the chest where the lymph node was found were: mediastinal in one patient, hilar in another patient, one pretreacheal and two patients were subcarinal with cervical lymph nodes. Supraclavicular and pretreacheal and perivascular (scattered) lymph nodes - on PET scan was detected in one patient. Three 
patients had RVD tests all of which were negative, and three patients had transbronchial lymph node biopsies all of which were negative for TB. Only one patient showed evidence of TB (on bronchial washing).

\section{Pulse deficit}

As shown in the table below, the majority (72\%) of our cohort had pulse deficits, and most of them involved the radial artery: on the right side $(36.1 \%)$ and on the left side in $(61.1 \%)$.

\begin{tabular}{|l|c|c|}
\hline \multicolumn{1}{|c|}{ Type } & $\begin{array}{c}\text { Frequency } \\
(\mathbf{n = 5 0 )}\end{array}$ & Percentage \\
\hline Left Radial & 22 & 61.1 \\
\hline Right Radial & 13 & 36.1 \\
\hline Right lower limb & 12 & 33.3 \\
\hline Left lower limb & 12 & 33.3 \\
\hline Left Carotid & 9 & 25 \\
\hline Right Carotid & 7 & 19.4 \\
\hline Right Femoral & 7 & 19.4 \\
\hline Left Brachial & 5 & 13.8 \\
\hline Left Femoral & 5 & 13.8 \\
\hline Right Brachial & 5 & 13.8 \\
\hline
\end{tabular}

Table 4: Pulse deficits

\section{Co-morbidity}

Table 5 shows the presence of co-morbidity in the cohort group. The majority of patients $(66 \% \mathrm{n}=32)$ had no co-morbidity.

There were 3 cases of active proven pulmonary tuberculosis (PTB) $(6 \%$ $\mathrm{n}=3$ ), two of whom were diagnosed on sputum testing and a third from bronchial washings. pulmonary hypertension was present in four patients. One patient had documented chronic thromboembolism and two had DCMO. The fourth patient had hypertensive heart disease.
One patient had interstitial lung disease but did not have pulmonary hypertension. Two patients had antiphospholipid antibody syndrome (APS), one of which had left carotid thrombosis and other one had cerebrovascular disease (2 strokes).

Five patients had retroviral disease (RVD). Two patients had chronic Hepatitis B, one patient had Arnold Chiari type1 with no syrinx; one patient had congenital heart disease; one patient had hypothyroidism, one had ureteric fistula, one patient had persistent haematuria (of unknown cause) and two patients had secondary syphilis.

\begin{tabular}{|l|c|c|c|}
\hline Item & Co-morbidity & $\begin{array}{c}\text { Frequency } \\
(\mathbf{n = 5 0 )}\end{array}$ & $\begin{array}{c}\text { Percentage } \\
(\mathbf{\%})\end{array}$ \\
\hline 1 & None & 32 & 64 \\
\hline 4 & RVD & 5 & 10 \\
\hline 5 & Pulmonary hypertension & 4 & 8 \\
\hline 6 & PTB & 3 & 6 \\
\hline 7 & Coronary artery disease & 3 & 6 \\
\hline 8 & Antiphospholipid & 2 & 4 \\
\hline 9 & Hepatitis & 2 & 4 \\
\hline 10 & Syphilis & 2 & 4 \\
\hline 11 & Hematuria & 1 & 2 \\
\hline 12 & Congenital heart disease & 1 & 2 \\
\hline 13 & Hypothyroidism & 1 & 2 \\
\hline 14 & Arnold-Chiari syndrome & 1 & 2 \\
\hline 15 & Structural lung disease & 1 & 2 \\
\hline & 1 & & \\
\hline
\end{tabular}

Table 5: Co-morbidities

\section{Angiographic classification}

In the current study, the new classification for TA was used as shown in Figure 2 below. 


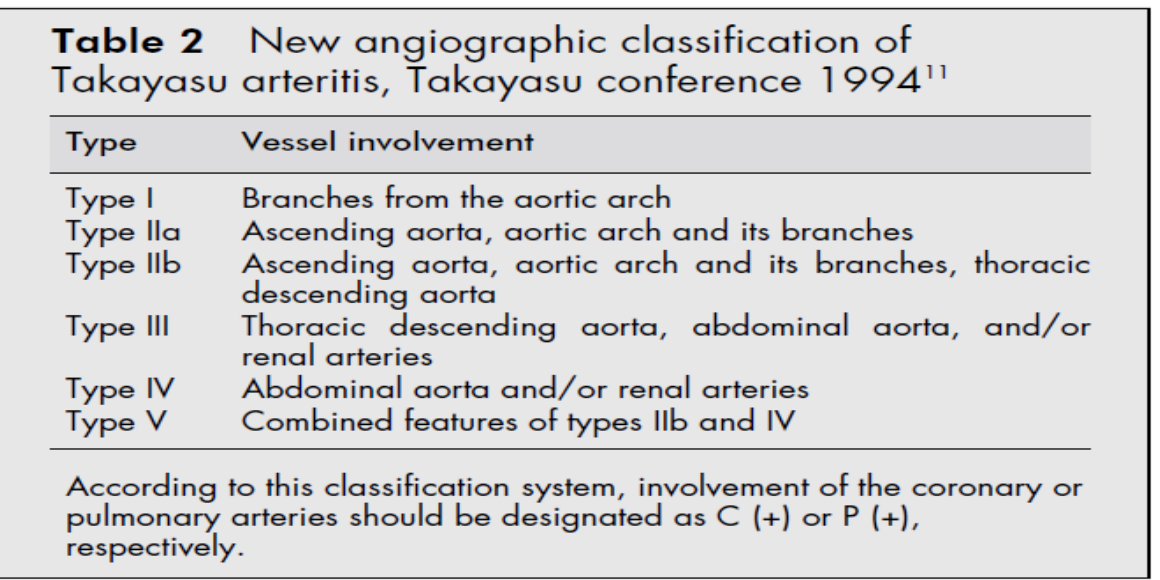

\section{Figure 2: New classification of TA}

In our cohort, the majority of patients met Type V (38\% $\mathrm{n}=19)$ of the ACR criteria. Type I was found in nine patients (18\% n=9), Type III was found in seven patients $(14 \% \mathrm{n}=7)$, Type IIa and IIb were found in two patients, respectively.

\begin{tabular}{|l|c|c|c|}
\hline Item & Type & Frequency $(\mathbf{n}=\mathbf{5 0})$ & Percentage (\%) \\
\hline 1 & Type V & 19 & 38 \\
\hline 2 & Type I & 9 & 18 \\
\hline 3 & Type III & 7 & 14 \\
\hline 4 & Type IV & 5 & 10 \\
\hline 5 & Type IIb & 2 & 4 \\
\hline 6 & Type IIa & 2 & 12 \\
\hline 7 & Not available & 6 & 100 \\
\hline
\end{tabular}

Table 6: Angiographic type

\section{Complications}

Table 9 shows complications related to disease and treatment. The majority of patients had HPT $(54 \% \mathrm{n}=27)$ which includes the earlier manifestation and subsequent complication with six patients reporting CVA $(12 \% \mathrm{n}=6)$.

Left Heart Failure was present in 6 patients. In four of these patients, this was assessed as being the result of severe hypertension and the other two was labeled "idiopathic".

Three of the patients of our total cohort suffered a stroke subsequently .Chronic kidney disease was present in 5 patients (10\%) and was thought to be mainly due to bilateral renal artery stenosis and severe hypertension.

Complication which occurred in 2 patients included optic nerve atrophy and glaucoma in another case. Valvular heart complications were present in 5 cases $(10 \%)$ in the form of mitral regurgitation in two patients and aortic regurgitation in another 3 patients.
The vascular complications (arterial or venous thrombosis) occurred in seven patients $(14 \% \mathrm{n}=7)$. Pulmonary embolism was found in two patients with no obvious underlying venous thrombosis. Two of the patients had jugular vein thrombosis and the remaining were arterial in nature. Two patients had thromboembolic to the coronary vessels one had an intramural thrombus in the left ventricle (patient with DCMO).

Chronic kidney disease was found in $(10 \%)$ of our patients where latest creatinine ranged from 140-180 umol/L.

Three patients $(6 \% n=3)$ had coronary artery disease (CAD), the aetiology of which may be multifactorial. As mentioned, two patients had thromboemboli from the left ventricle and a third had diffuse atherosclerotic disease. A similar percentage of $(6 \% n=3)$ was preset in patients who had peripheral vascular ischemia with evidence of gangrene in lower limbs and in the mesenteric vasculature. Steroid induced Cushing syndrome was present in two patients $(4 \% \mathrm{n}=2)$.

\begin{tabular}{|l|c|c|}
\hline Complication & Frequency $(\mathbf{n}=\mathbf{5 0})$ & Percentage \\
\hline Hypertension & 27 & 54 \\
\hline Vascular thrombosis & 7 & 14 \\
\hline CVA & 6 & 12 \\
\hline Congestive cardiac failure & 6 & 12 \\
\hline Ophthalmic complication & 2 & 10 \\
\hline
\end{tabular}




\begin{tabular}{|l|c|c|}
\hline $\begin{array}{l}\text { Valvular Disease } \\
\text { (Aortic/Mitral) }\end{array}$ & 5 & 10 \\
\hline CKD & 5 & 10 \\
\hline Hypertensive heart disease & 4 & 8 \\
\hline Peripheral gangrene & 3 & 6 \\
\hline Coronary artery disease & 3 & 6 \\
\hline Epilepsy & 3 & 4 \\
\hline Cushing syndrome & 2 & 2 \\
\hline DM & 1 & 2 \\
\hline Psychosis & 1 & 6 \\
\hline
\end{tabular}

Table 7: Complications

\section{Incidence of HIV among TA patients}

A total of 34 patients were tested for HIV (68\%) in our cohort. Almost $15 \%(14.7 \%)$ of the patients who were tested were positive, thus the majority $(85 \%)$ of the patients who were tested were negative.

\section{Incidence of Tuberculosis among TA patients}

Among our cohort, 20 patients (40\%) were tested for TB. The majority $(85 \%)$ of the tested population were negative, while 3 patients $(15 \%)$ tested positive. It is important to note TB testing was based on clinical suspicion.

\section{Imaging}

The majority $(88 \% \mathrm{n}=44)$ of the patients in this cohort had CTA and PET SCAN $(88 \% \mathrm{n}=44)$ each. PET SCAN is sometimes repeated as a follow up in detecting evidence of disease flare - 39 patients had both CTA and PET and 4 had only CTA). Half of patients (50\% $n=25)$ had Doppler, which is usually used as the initial diagnostic tool to confirm vasculature abnormality. In this cohort study, Doppler was frequently used in $(50 \%)$ of patient to assess the renal and carotids. Only ten patients $(20 \% \mathrm{n}=10)$ had an MRI.

\begin{tabular}{|l|c|c|}
\hline Radiological modality & Frequency $(\mathrm{n}=50)$ & Percentage $(\%)$ \\
\hline CTA & 44 & 88 \\
\hline PET SCAN & 44 & 80 \\
\hline DOPPLER & 25 & 50 \\
\hline MRI & 10 & 20 \\
\hline
\end{tabular}

Table 8: Radiological modality

\section{Angiographic (CTA) findings}

The majority (58\%) had stenosis, followed by stenosis and aneurysm in (32\%) as shown in the table below.

\begin{tabular}{|l|c|c|}
\hline Artery involved & Frequency $(\mathrm{n}=50)$ & Percentage $(\%)$ \\
\hline Subclavian artery & 21 & 42 \\
\hline Abdominal aorta artery & 18 & 36 \\
\hline Common carotid artery & 16 & 32 \\
\hline Bilateral renal artery & 14 & 28 \\
\hline Thoracic aorta & 13 & 26 \\
\hline Unilateral renal artery & 8 & 16 \\
\hline Mesenteric artery & 6 & 12 \\
\hline Arch of Aorta & 5 & 10 \\
\hline Ascending Aorta & 5 & 10 \\
\hline Vertebral artery & 5 & 10 \\
\hline Brachiocephalic artery & 3 & 6 \\
\hline Iliac artery & 3 & 6 \\
\hline Pulmonary artery & 1 & 2 \\
\hline
\end{tabular}

Table 9: Angiographic findings

\begin{tabular}{|l|c|c|}
\hline Type & Frequency $(\mathrm{n}=50)$ & Percentage (\%) \\
\hline Stenosis & 29 & 58 \\
\hline Both & 16 & 32 \\
\hline Aneurysmal & 2 & 4 \\
\hline Unknown & 3 & 6 \\
\hline Total & 50 & 100 \\
\hline
\end{tabular}

Table 10: Type of lesions 


\section{Medical treatment}

Different types of options for treatment are available to TA patients depending on the course of the disease. The majority of patients $(60 \%$ $\mathrm{n}=30$ ) were treated with a combination of treatments including methotrexate or azathioprine with steroids.

Ten patients $(20 \%)$ reported not being on treatment, due to "burnt-out" disease or patients did not have active disease at the time.
Two patients received biologics; one received (Infliximab) and the other received tocilizumab.

Four patients $(8 \% \mathrm{n}=4)$ were treated with steroids only (Prednisone).

The efficacy of each treatment was not included in our study

\begin{tabular}{|l|c|c|}
\hline Treatment & Frequency $(\mathrm{n}=50)$ & Percentage $(\%)$ \\
\hline Combination & 30 & 60 \\
\hline Prednisone only & 4 & 8 \\
\hline Methotrexate only & 3 & 6 \\
\hline Azathioprine only & 2 & 4 \\
\hline Biologics & 2 & 4 \\
\hline None & 10 & 20 \\
\hline
\end{tabular}

Table 11: Treatment regimens

\section{Surgical interventions}

Some patients had surgical intervention to treat complications arising from the disease. Twelve patients $(24 \% \mathrm{n}=12)$ had renal surgical intervention which included four of them undergoing autotransplantation. Five patients had renal artery graft, two patients had nephrectomy and one had kidney transplant. Furthermore, five patients $(10 \% \mathrm{n}=5)$ had aortic complications requiring surgical intervention, which included repair of AAA and arch of the aorta. Lastly, one patient case required repair of root of the aorta, which included aortic valve replacement. Two of patients required amputation, one had one toe amputated and the other two left fingers amputat

\begin{tabular}{|l|c|c|}
\hline Treatment & Frequency $(\mathrm{n}=50)$ & Percentage (\%) \\
\hline Renal & 12 & 24 \\
\hline Aorta & 5 & 10 \\
\hline Amputation & 2 & 4 \\
\hline
\end{tabular}

Table 12: Surgical intervention

\section{Mortality rates}

Two patients (4\%) died which both as a result of massive strokes.

\section{Discussion}

\section{Demographics}

In terms of age distribution, our findings report a mean age of 28.2 years (16-56) years which is consistent with the Brazilian study (27 years) [19], the one Tunisian study (29.1) [15] and Groote Schuur series (25 years). [4] Higher mean ages were noted in the other Tunisian study (33.2 years) [16] and Turkish series (40 years). [18] In terms of ethnic distribution, our findings show that TA was predominantly found among the mixed-race group, which is similar to that of the GSH study. [21] The reason is that the Western Cape has a predominantly mixed-race population which explains the difference to the Gauteng series, where the majority of the population are of African ethnicity (black). [12] Gender distribution in this study among TA patients is supported by similar studies confirming the predominant female involvement $(82 \%)$ and is consistent with other series by GSH (75\%) [21], Turkish study (91.9\%) [18], Tunisian study $(88.9 \%)$ [15] and the Brazilian study. [19]

\section{Hypertension}

Hypertension was the most common presentation in TA patients. Over half of patients in this series (54\%) presented with hypertension and is consistent with the with GSH series (77\%) [21], Turkish series (43\%) [18] and Greek series (78.0\%). [4] The pathogenesis of the hypertension is postulated as being due to renal artery stenosis in most cases or "coarctation of the aorta" in other cases. It should be noted that the majority of the patients had category Type V (38\%) which affects the ascending aorta, aortic arch and its branches, and thoracic descending aorta as well as abdominal aorta and/or renal artery.

\section{Prevalence of active TB}

Theoretically, patients with TA have suppressed immunity. This is thought to be due to the immune mediated nature of the disease as well as the treatment with steroids and other immunosuppressive therapy.

In our cohort, $10 \%$ of our patients tested positive for TB. However, although all patients were subjected to an appropriate history-taking and had a chest radsiograph, extensive testing for TB was not conducted on those patients assessed as not likely to have TB. Thus, the TB status of the majority $(60 \%)$ was not known. Definitive exclusion of TB was also not conducted in other studies. However, a low prevalence of TB of only $6 \%(n=3)$ is unexpectedly lower in comparison to other studies. This is of particular significance considering the fact that patients in our cohort hail from a predominantly poor and disadvantaged communities where there is a pandemic of TB.

A more direct comparison can be made to the GSH study where the proportion of TA patients diagnosed with TB was as high as 20\%. [21] A potential problem with the diagnosis of $\mathrm{TB}$ in this series was that a strongly positive Mantoux was also regarded as evidence of "active" TB. Currently routine Mantoux screening as evidence of TB is not the norm. In terms of TB prevalence, the Korean series reported prevalence of $17 \%$, Turkish series $(6.4 \%)^{\mathrm{i}}$ and the Brazilian study $41.0 \%$.[19] Generally a high percentage of TB (up to $90 \%$ ) has been reported in pediatric series including the South African study. 


\section{Lymphadenopathy}

Although lymphadenopathy is a well-documented finding in patients with $\mathrm{TA}$, the presence of large mediastinal nodes mimicking $\mathrm{TB}$ is rare. Current literature reports isolated cases of "massive" lymphadenopathy mimicking TB. In our cohort, six patients $(12 \% \mathrm{n}=6)$ had significant lymphadenopathy. In these cases; however, it is mandatory to exclude TB. Although one patient clearly had TB, evidence of TB for the remainder of the population was not available. It may be suggested that previous cases of severe lymphadenopathy due to TA, may have been regarded as being due to TB and in some cases, were subjected to anti-TB treatment. This is the first study that documents significant lymphadenopathy in $10 \%$ of the cases of TA.

\section{Venous thrombosis}

Two patients in this study had internal jugular vein thrombosis and two had the CTA proven pulmonary embolism. However, there was no obvious site of venous thrombosis evident in the patients with pulmonary embolism. As TA is a disease affecting large arteries, venous thrombosis did not form part of the clinical features of this condition. Internal jugular vein thrombosis is also very rare, but 2 cases were evidenced in our cohort. Furthermore, isolated case reports relating to venous thrombosis and one reporting on internal jugular vein thrombosis have been noted. [5]

Two female patients of our cohort had antiphospholipid syndrome increasing the risk of venous and arterial thrombosis. The rarity is clear because the literature search revealed the association of TA with antiphospholipid syndrome as 2 case reports, one from Korea in which an elderly female was affected [5], and in the other a young Japanese man (17 years old). [6]

\section{Cardiomyopathy:}

Although 6 patients presented with heart failure, two of the cases did not have a clear cause such as severe hypertension or ischaemic heart disease. We feel that it is reasonable to assume that these cases were due to the rare entity of TA associated cardiomyopathy. Furthermore, there was no data exploring this topic, only a case report of TA presented with heart failure. [6]

\section{HIV}

In this study only 34 of the 50 patients were tested for HIV. HIV testing was not routinely done but reserved for those with underlying clinical suspicion of this condition. Thus, just under $15 \%$ of those tested were positive for HIV making it very difficult to draw any meaningful conclusions on the effect of this condition. From the limited numbers who were HIV positive, it does not appear that this condition presented differently in this sub group.

\section{Imaging}

In our patients the commonest vessel affected was the subclavian artery $(42 \%)$ and is consistent the Gauteng pediatric study (52.2\%) and the

\section{References}

1. Onen F, Akkoc N. Epidemiology of Takayasu arteritis. La Presse Médicale. 2017 Jul 1;46(7-8):e197-203.

2. Sharma BK, Jain S. A possible role of sex in determining distribution of lesions in Takayasu arteritis. International journal of cardiology. 1998 Oct 1;66:S81-4.
Tunisian series. In the GSH series, 70\% involved the entire aorta. [21] Our study showed that most TA patients had Type V (32\%), which mirrors the findings of the Brazilian series (52\%). [19]

CT angiogram has been and remains the imaging method of choice for the diagnosis of TA. Most of the patients had Type V disease, which was also the case in the GSH study. PET CT scanning has been shown to be a good adjunctive method of imaging in cases where there may be uncertainty on whether there is active vasculitis in the patient or not. The radiographic findings characteristic on CTA, namely stenosis and aneurysm formation, do not necessarily imply active disease. In this study, $80 \%$ of the patients had PET-CT scanning done, some of whom had more than one. This number is much larger than that which have reported previously and it appears that this may become a routine part of the follow up if there is a need to determine "active" TA.

\section{Mortality}

In this study only 2 patients (4\%) died. This represents a low mortality compared to previous reports and is a much lower than the mortality than that reported from the GSH of 20\%.[21] This may reflect earlier and improved diagnosis of milder cases which may have been missed in the past or, may be due to alternative therapies which were not available previously (see below). [17]

\section{Treatment}

Largely because of limitation of state resources, only two patients received biologic therapy. One patient received infliximab and the other patient received infliximab which caused reactivation of TB. She subsequently received tocilizumab and is currently still on this treatment.

\section{Conclusion}

In summary this study revealed gender and age characteristics similar to previous studies, confirming that TA affects mainly young females. The mortality rate of $6 \%$ in this cohort is significantly lower than that reported in previous series.

Some of the unexpected findings in this study was the significantly lower percentage of active TB. This study also revealed 6 cases of "massive" chest lymphadenopathy only one of which was due to TB. It may well be that some of the TB cases reported in previous studies may have been over-diagnosed.

This study also revealed two (2) unusual cases of venous thrombosis supporting isolated previous reports of venous thrombosis.

Another previously documented but rare finding in TA was that there were 2 cases of cardiomyopathy in our cohort.

A prospective study involving larger numbers from different institutions may shed some light on these intriguing findings

3. Lim AY, Lee GY, Jang SY, Gwag HB, Choi SH, Jeon ES, Cha HS, Sung K, Kim YW, Kim SM, Choe YH. (2015) Gender differences in clinical and angiographic findings of patients with Takayasu arteritis. Clinical and experimental rheumatology. 33(2 Suppl 89):S-132. 
4. Maffei S, Di Renzo M, Bova G, Auteri A, Pasqui AL. Takayasu's arteritis: a review of the literature. Internal and emergency medicine. 2006 Jul 1;1(2):105-112.

5. Arend WP, Michel BA, Bloch DA, Hunder GG, Calabrese LH, Edworthy SM, Fauci AS, Leavitt RY, Lie JT, Lightfoot Jr RW, Masi AT. The American College of Rheumatology 1990 criteria for the classification of Takayasu arteritis. Arthritis \& Rheumatism. 1990 Aug;33(8):1129-1134.

6. Andrews J, Al-Nahhas A, Pennell DJ, Hossain MS, Davies KA, Haskard DO, Mason JC. Non-invasive imaging in the diagnosis and management of Takayasu's arteritis. Annals of the rheumatic diseases. 2004 Aug 1;63(8):995-1000.

7. De Leeuw K, Bijl M, Jager PL. Additional value of positron emission tomography in diagnosis and follow-up of patients with large vessel vasculitides. Clin Exp Rheumatol. 2004 Nov 1;22(6 Suppl 36):S21-26.

8. Chaubal N, Dighe M, Shah M. Sonographic and color Doppler findings in aortoarteritis (Takayasu arteritis). Journal of ultrasound in medicine. 2004 Jul 1;23(7):937-944.

9. Andrews J, Al-Nahhas A, Pennell DJ, Hossain MS, Davies KA, Haskard DO, Mason JC. Non-invasive imaging in the diagnosis and management of Takayasu's arteritis. Annals of the rheumatic diseases. 2004 Aug 1;63(8):995-1000.

10. Cheng, Y., Lv, N., Wang, Z., Chen, B., \& Dang, A. (2013). 18FDG-PET in assessing disease activity in Takayasu arteritis: a meta-analysis. Clin Exp Rheumatol, 31(1 Suppl 75), S22-S27

11. Seyahi E. Takayasu arteritis: an update. Current opinion in rheumatology. 2017 Jan 1;29(1):51-56.

12. Hahn D1, Thomson PD, Kala U, Beale PG, Levin SE. A review of Takayasu's arteritis in children in Gauteng, South Africa. Pediatr Nephrol. 1998 Oct;12(8):668-675.

13. Cilliers AM1, Adams PE1, Ntsinjana H1, Kala U2.Review of children with Takayasu's arteritis at a Southern African tertiary care centre. Cardiol Young. 2018 Sep;28(9):1129-1135. doi: 10.1017/S1047951118000938. Epub 2018 Jul 6.

14. Cooper K1, Chetty R. Takayasu's aorto-arteritis. A report of 11 cases at King Edward VIII Hospital, Durban. S Afr Med J. 1987 Nov 21;72(10):711-713.

15. Ghannouchi NJ, Khalifa M, Rezgui A, Alaoua A, Ben EJ, Braham A, Kechrid C, Mahjoub S, Ernez S, Boughzela E, Ben MF. Takayasu's disease in central Tunisia: 27 cases. Journal des maladies vasculaires. $2010 \mathrm{Feb}$;35(1):4-11.

16. Ben Dhao, B, Aydi, Z, Boussema, F, Ben Dahmen, F, Baili, L, Ketari, S, Kochbati, S, Quahida, S, Rokbani, L. Takayasu's disease in Tunisia: Monocentric study of 11 cases.2012, 90 (012):867-872.

17. Tazi-Mezalek, Z., Aouni, M., Adnaoui, M., Mohattane, A., Bensaid, Y., \& Maaouni, A. (2002). Takayasu's disease in Morocco. Report of 47 cases. La Revue de medecine interne, 23(1), 9-20

18. Bicakcigil M, Aksu K, Kamali S, Ozbalkan Z, Ates A, Karadag O, Ozer HT, Seyahi E, Akar S, Onen F, Cefle A. Takayasu's arteritis in Turkey - clinical and angiographic features of 248 patients. Clinical \& Experimental Rheumatology. 2009 Jan 1;27(1):S59.

19. Sato EI, Hatta FS, Levy-Neto M, Fernandes S. Demographic, clinical, and angiographic data of patients with Takayasu arteritis in Brazil. International journal of cardiology. 1998 Oct 1;66:S67-70.

20. Sharma BK, Jain S, Suri S, Numano F. Diagnostic criteria for Takayasu arteritis. International journal of cardiology. 1996 Aug 1;54: S141-147.

21. Mwipatayi, B. P., Jeffery, P. C., Beningfield, S. J., Matley, P. J., Naidoo, N. G., Kalla, A. A., \& Kahn, D. (2005). Takayasu arteritis: clinical features and management: report of 272 cases. ANZ journal of surgery, 75(3), 110-117.

22. Karageorgaki ZT1, Bertsias GK, Mavragani CP, Kritikos HD, Spyropoulou-Vlachou M, Drosos AA, Boumpas DT, Moutsopoulos HM. Takayasu arteritis: epidemiological, clinical, and immunogenetic features in Greece. Clin Exp Rheumatol. 2009 Jan-Feb;27(1 Suppl 52):S33-39.

23. Karadag O, Aksu K, Sahin A, Zihni FY, Sener B, Inanc N, Kalyoncu U, Aydin SZ, Ascioglu S, Ocakci PT, Bilgen SA. Assessment of latent tuberculosis infection in Takayasu arteritis with tuberculin skin test and Quantiferon-TB Gold test. Rheumatology international. 2010 Sep 1;30(11):1483-1487.

24. Maamouri, H., Larbi, T., Hamzaoui, S., Elouni, A., Bouslama, K., \& M'rad, S. (2015). AB0647 Veins Thrombosis Occuring in Takayasu Arteritis: Causal or Casual Relation?

25. Lee, H, Hwang, JP, Kim, HS. Takayasu Arteritis and antiphospholid antibody syndrome in an elderly woman. 2015. Korean J Intern Med, (30)6:934-937. PMID: 26552473

26. Fukui, S, Hirota, S, Iwamoto, N, Karata, H, Kawakami, A. Takayasu arteritis with antiphosphatidylserine/Prothrombin Antibody-Positive Antiphospholid Syndrome. 2015. Medicine Balitimore, 94(51):e2345. PMID:26705229.

27. An, X, H;an, Y, Zhang, B, Qiao, L, Zhao, Y, Guo, X, Fang, L, Zhu, W, Fang, Q, Shen, Z, Zhang S. 2017; Sep, ESC Heart Failure, 4:649-654. DOI: 10.1002/ehf2.12174. 
Ready to submit your research? Choose Auctores and benefit from:

* fast, convenient online submission

* rigorous peer review by experienced research in your field

* rapid publication on acceptance

* authors retain copyrights

* unique DOI for all articles

* immediate, unrestricted online access

At Auctores, research is always in progress.

Learn more www.auctoresonline.org/journals/clinical-cardiology-andcardiovascular-interventions 